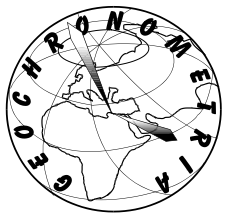

Conference Proceedings of the $4^{\text {th }}$ Asia Pacific Luminescence and Electron Spin Resonance Dating Conference Nov $23^{\text {rd }}-25^{\text {th }}, 2015$, Adelaide, Australia

Guest Editor: Nigel Spooner

\title{
CATHODOLUMINESCENCE COLOR ZONATION IN THE ANTARCTIC METEORITE (ENSTATITE CHONDRITE) OF YAMATO 86004
}

\author{
SYUHEI OHGO ${ }^{1}$, MAKI MISHIMA ${ }^{2}$, MINORU ENDO ${ }^{2}$, \\ KIYOTAKA NINAGAWA ${ }^{2}$ and HIROTSUGU NISHIDO ${ }^{1}$ \\ ${ }^{l}$ Department of Biosphere-Geosphere Science, Okayama University of Science, \\ 1-1 Ridaicho, Kitaku, Okayama, Okayama, 700-0005 Japan \\ ${ }^{2}$ Department of Applied Physics, Okayama University of Science, \\ 1-1 Ridaicho, Kitaku, Okayama, Okayama 700-0005, Japan
}

\begin{abstract}
Enstatite in Yamato 86004 classified as EH melt rock shows cathodoluminescence (CL) zonation as arranged in a concentric pattern from within outward blue, light blue, red and non-CL areas (fusion crust). The zonation observed in the meteorite results from different distribution ratio of the enstatite with various CL colors. CL spectra of the enstatite have two broad emission bands at around $400 \mathrm{~nm}$ in the blue region and at around $670 \mathrm{~nm}$ in a red region. The emission components obtained by a spectral deconvolution can be assigned to three defect centers $(2.73,3.13-3.15$ and $3.77 \mathrm{eV})$ in a blue region and to impurity centers of $\mathrm{Cr}^{3+}$ ion $(1.71 \mathrm{eV})$ and $\mathrm{Mn}^{2+}$ ion $(1.86-1.91 \mathrm{eV})$ in a red region. According to the CL related to structural defects in the enstatite, blue-CL enstatite might be originally formed from the melt by a quenching from the melt on the surface of parent body. The enstatite with light blue and red CL might be thermally altered from blue-CL enstatite with phase transitions during a flash heating when the meteorite passed through the atmosphere. Therefore, the color CL zonation reflects a thermal history recorded in the meteorite.
\end{abstract}

Keywords: enstatite, cathodoluminescence, enstatite chondrite, Antarctic meteorite.

\section{INTRODUCTION}

Cathodoluminescence (CL) is a visible light of emissions when a material is irradiated by an electron beam. The luminescence phenomenon mainly occurs due to a presence of specific luminescence center due to lattice defect or impurity. The CL features in minerals are close-

Corresponding author: S. Ohgo e-mail: s.ohgo0628@gmail.com ly related to varieties of emission centers such as the impurity concentration, defect density, crystal fields (e.g., Marfunin, 1979). Therefore, a CL method has a high advantage to reveal internal textures, growth zoning and antigenic minerals, which are difficult to identify by conventional optical examinations such as a polarization microscopy (e.g., Matsunami et al., 1993). Recently, CL microscopy and spectroscopy have been extensively used for planetary sciences to characterize extraterrestrial minerals, most of which were formed under unusual conditions such as shock metamorphism, hightemperature melting and super-reductive environment 
(e.g., Gucsik, 2009). A CL color imaging was employed to evaluate a petrologic type of enstatite chondrite (Echondrite) formed in a reducing environment (e.g., Zhang et al., 1996), which is divided into two groups of EL and $\mathrm{EH}$ chondrite by remaining chondrule size and $\mathrm{Fe}-\mathrm{Ni}$ metal abundance. The EH chondrite exhibits a brighter blue $C L$ in the enstatite at higher petrologic type, whereas the EL chondrite has the enstatite at higher petrologic type with a brighter magenta CL.

Enstatite is one of most important rock-forming minerals in the terrestrial and extraterrestrial materials. The enstatite $\mathrm{CL}$ in the meteorites has been investigated to reveal their thermal histories (e.g., Derham et al., 1964; Keil, 1968; Zhang et al., 1996). Most of enstatite which emits various CL has been found in E-chondrite and enstatite achondrite (Aubrite). Major silicate phase in Echondrite and Aubrite is a near endmember of enstatite $(\mathrm{FeO}<1.0 \%)$. Minute amounts of quencher ions such as $\mathrm{Fe}^{2+}$ ion by the segregation of metal iron under a reductive condition (e.g., Keil, 1968, Weisberg et al., 1994) result in various CL emissions with red, purple and blue (Reid et al., 1964).

Yamato 86004 (hereafter Y-86004) is one of Antarctic E-chondrite classified as an EH melt rock, which is characterized by constituent minerals having a feature of crystallization from melts with an Abee matrix (Rubin and Scott, 1997). We have found a CL zonation composed the enstatite with various color in Y-86004 for the first time from the meteorites. In this study, we have conducted to clarify the CL zonation in Y-86004 using $\mathrm{CL}$ color imaging and spectroscopy for estimating a thermal history of the meteorite.

\section{SAMPLE AND METHODS}

The sample of Y-86004 was provided as a polished thin section by the National Institute of Polar Research (NIPR), Japan. It is a rounded shape with $\sim 4.5 \mathrm{~mm}$ in diameter (Fig. 1b). Y-86004 was identified as an E6 chondrite by Yanai and Kojima (1995). Subsequently, it has been classified into a EH melt rock judging by petrographical and mineralogical characteristics (Lin and Kimura, 1998).

CL color images were obtained using the Luminoscope (ELM-3), attached with a cooled charge-coupled device (CCD) camera, which consists of a cold cathode discharge tube and a vacuum chamber in which the sample is placed. It was operated stably with electron beams generated by an excitation voltage of $15 \mathrm{kV}$ and a beam current of $0.5 \mathrm{~mA}$. CL spectroscopy was carried out by an SEM-CL system, which consists of an SEM (JEOL, JSM$5410 \mathrm{LV}$ ) combined with a grating monochromater (Oxford, Mono CL2) with operating conditions of $15 \mathrm{kV}$ and $1.0 \mathrm{nA}$ in a scanning mode. The CL emitted from the sample was collected in the range of 300-800 nm with a photomultiplier tube by a photon counting method. All CL spectra were corrected for total instrumental response, which was measured using of a calibrated standard lamp (Eppley Laboratory: Quartz Halogen Lamp). This correction prevents errors in the peak position of emission bands and allows quantitative evaluation of CL intensity. Detailed construction of the equipment and the analytical procedure can be found in Ikenaga et al. (2000). Crystalchemical characterization of the constituent minerals was performed using the JXA-8230 electron probe microanalyzer (EPMA) and Nicolet Almega-XR Raman spectrometer.

\section{RESULTS AND DISCUSSION}

Y-86004 shows a rounded shape of $\sim 4.5 \mathrm{~mm}$ diameter in a thin section, which is completely surrounded by a fusion crust. It exhibits no texture with chondrules and chondrule fragments under a polarizing microscope. According to EPMA and Raman spectroscopy analyses, the meteorite contains orthopyroxine of near-end-member enstatite $(20-200 \mu \mathrm{m})$, opaque minerals of metallic Fe-Ni and troilite (up to $200 \mu \mathrm{m}$ ), plagioclase with albite composition (up to $30 \mu \mathrm{m}$ ) and silica mineral of tridymite (up to $120 \mu \mathrm{m})$ and glassy materials mostly in the fusion crust. Orthoenstatite (Oen) is predominant phase, which occurs as euhedral lath-shape grains, which usually protrude into or enclosed in opaque minerals. Plagioclase and silica mineral are commonly found as interstitial materials in the Oen grains. The petrographic texture characterized by enstatite occurrences in Y-86004 is similar to that observed in the EH melt rock, which may
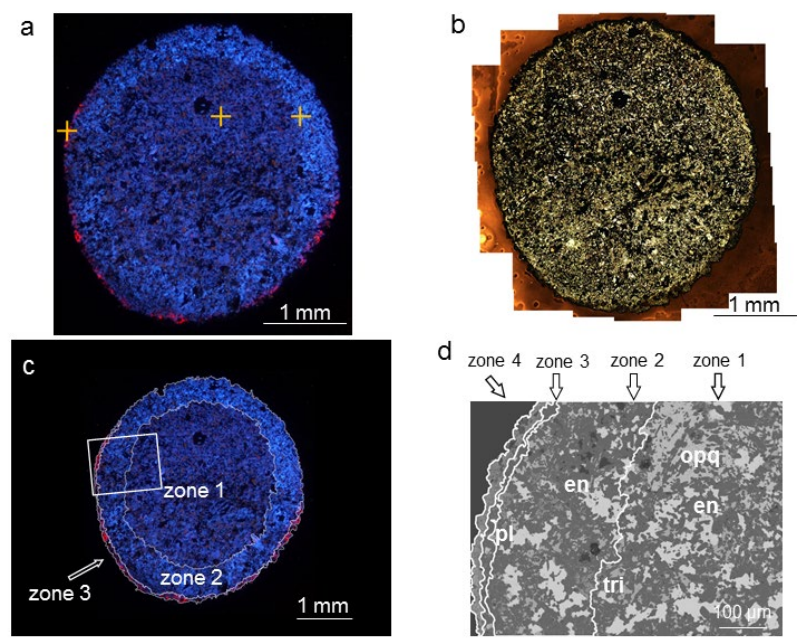

Fig. 1. (a) Color CL image of $Y-86004$. Yellow cross marks indicating the positions in CL-spectral measurement. (b) Parallel-polarizing microscope image of Y-86004 corresponding to the area in Fig. 1a. (c) Color-CL image of $\mathrm{Y}-86004$ indicating boundaries between each zone. Zone 1: blue-CL area, zone 2: light-blue-CL area, zone 3: red-CL area. (d) BSE image of $Y-86004$ corresponding to the area indicating a square in Fig. 1c. Zone 1: blue-CL area, zone 2: light-blue CL area, zone 3: red-CL area, zone 4: non-CL area (fusion crust). en: enstatite, tri: tridymite, pl: plagioclase and opq: opaque minerals. 
have experienced an impact melt near the surface of the parent body (Rubin and Scott, 1997; Lin and Kimura, 1998). However, Y-86004 has no impact-shock textures (e.g., planar fractures, clinoenstatite lamellae, and mosaicism) in the constituent minerals.

Chemical compositions of the enstatite with different $\mathrm{CL}$ color are compiled on an average of six analyses per grain by EPMA (WDS) in Table 1, additionally with glassy material in the fusion crust. Each enstatite is a nearly end member with low $\mathrm{FeO}$ contents $(<1$ wt.\%), whereas glassy material has a similar composition pyroxene (diopside) with high $\mathrm{FeO}$ contains (> 30 wt.\%).

\section{CL observation}

Y-86004 shows a rounded shape with blue luminescence as the whole pattern in a color CL image (Figs. 1a and 1c), whereas it has a thin red rim. According to Zhang et al. (1996), the EH chondrite with a higher petrographic type (e.g., EH5 chondrite) exhibits more predominant blue CL in contrast with red CL for that with a low petrographic type (e.g., EH3 chondrite). Therefore, Y-86004 should be corresponding to E-chondrite judging from its CL color.

The enstatite with low $\mathrm{FeO}$ contents $(<5$ wt.\%) in Echondrites shows visible CL due to a negligibly small concentration of quencher (e.g., Keil, 1968; Weisberg et al., 1994), which is mostly $\mathrm{Fe}^{2+}$ ion. Extrinsic luminescence of enstatite should be controlled mainly by the concentrations of activators $\left(\mathrm{Mn}^{2+}\right.$ and $\mathrm{Cr}^{3+}$ ions) and quencher $\left(\mathrm{Fe}^{2+}\right.$ ion).

Color CL imaging in the thin section reveals a concentric zonation mainly attributable to the distribution of the enstatite different in color as arranged from within outward blue CL (zone 1), light blue CL (zone 2), red CL (zone 3) and non-CL zone (zone 4) corresponding to a fusion crust (Figs. 1a and 1c). BSE image (Fig. 1d) shows none of concentric features as found in a color CL image, neither in the petrographic examination under a

Table 1. Chemical compositions on an average of three analyses of the enstatite with different $C L$ colors and fusion crust in each zone. n.d.: not detected.

\begin{tabular}{|c|c|c|c|c|c|}
\hline & $\begin{array}{c}\text { Enstatite in } \\
\text { zone } 1\end{array}$ & $\begin{array}{c}\text { Enstatite in } \\
\text { zone } 2\end{array}$ & $\begin{array}{l}\text { Enstatite in } \\
\quad \text { zone } 3\end{array}$ & $\begin{array}{c}\text { Fusion } \\
\text { crust in } \\
\text { zone } 4\end{array}$ & \\
\hline$\overline{\mathrm{SiO}_{2}}$ & 59.80 & 59.96 & 59.20 & 53.90 & wt. $\%$ \\
\hline $\mathrm{TiO}_{2}$ & n.d. & 0.01 & n.d. & n.d. & \\
\hline $\mathrm{Al}_{2} \mathrm{O}_{3}$ & 0.11 & 0.10 & 0.07 & 4.24 & \\
\hline $\mathrm{FeO}$ & 0.43 & 0.11 & 0.60 & 30.60 & \\
\hline $\mathrm{Cr}_{2} \mathrm{O}_{3}$ & 0.02 & n.d. & 0.02 & 0.39 & \\
\hline $\mathrm{MnO}$ & n.d. & n.d. & 0.04 & 0.94 & \\
\hline $\mathrm{MgO}$ & 39.81 & 39.74 & 39.48 & 5.05 & \\
\hline $\mathrm{CaO}$ & 0.26 & 0.28 & 0.24 & 3.55 & \\
\hline $\mathrm{NiO}$ & 0.01 & 0.01 & 0.06 & n.d. & \\
\hline $\mathrm{Na}_{2} \mathrm{O}$ & 0.01 & n.d. & n.d. & 1.41 & \\
\hline $\mathrm{K}_{2} \mathrm{O}$ & 0.01 & 0.01 & 0.01 & n.d. & \\
\hline Total & 100.46 & 100.22 & 99.73 & 100.00 & \\
\hline
\end{tabular}

polarizing microscope (Fig. 1b). Concentric CL zoning has been found in the meteorites for the first time, although a concentric CL image was observed only in the chondrule (forsterite) in Semarkona chondrite (Matsunami et al., 1993).

Average width of each band in the zonation is $\sim 1.50$ $\mathrm{mm}$ for zone $1, \sim 700 \mu \mathrm{m}$ for zone $2, \sim 100 \mu \mathrm{m}$ for zone 3 and $\sim 80 \mu \mathrm{m}$ for zone 4 . Zone 1 and 2 consist of blue and light blue enstatite, dark blue tridymite, reddish-brown plagioclase, and non-CL grains of opaque minerals. These zones have similar petrographic texture, however, the distribution ratio of light-blue-CL enstatite in zone 2 is higher than that of zone 1 . Zone 3 is characterized by red-CL enstatite with opaque minerals, but no tridymite. Zone 4 composed of glassy materials including blebs and opaque minerals exhibits no emission, suggesting heating above the melting temperature of the enstatite. Therefore, color CL zonation consisted of the enstatite with various colors should record a thermal history of the meteorite in the process of rapid heating and quenching during a flash heating when it entered into the atmosphere.

\section{CL spectroscopy and spectral deconvolution}

The CL spectra of the enstatite in each zone are shown in Fig. 2. All of them have two broad emission bands at around $400 \mathrm{~nm}$ in a blue region and at around $670 \mathrm{~nm}$ in a red region. Spectral deconvolution of the CL using a Gaussian curve fitting were carried out to clarify the emission components derived from various emission centers by the method proposed by Ohgo et al. (2015). The results of the spectral deconvolution reveal five emission components in their spectra (Figs. 3, 4, and 5). The component at $1.71 \mathrm{eV}$ is assigned to an impurity center activated by $\mathrm{Cr}^{3+}$ ion substituted for $\mathrm{Mg}$ in $\mathrm{M} 1$ site as an electron transition of ${ }^{4} \mathrm{~T}_{2} \rightarrow{ }^{4} \mathrm{~A}_{2}$. The component at $1.86-1.91 \mathrm{eV}$ is ascribed to an impurity center of $\mathrm{Mn}^{2+}$ ion substituted for $\mathrm{Mg}$ in $\mathrm{M} 2$ site as an electron transition

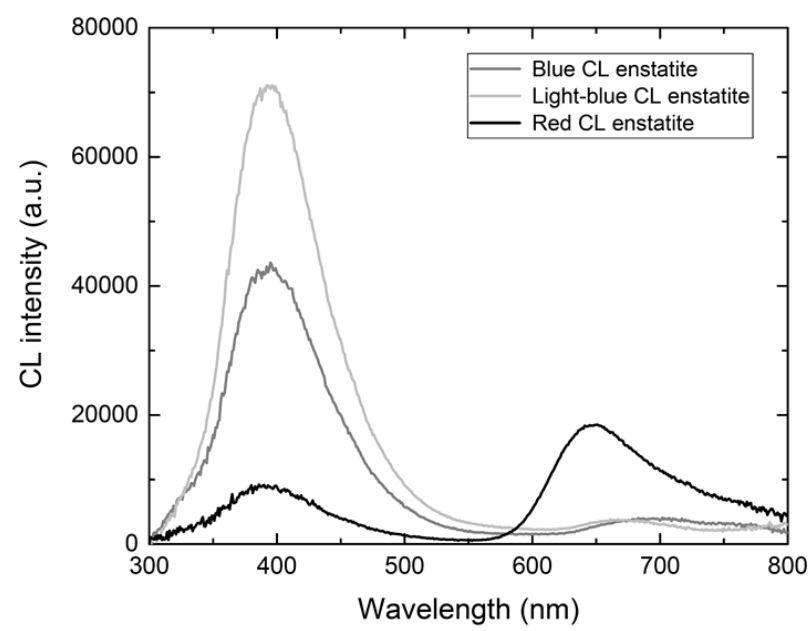

Fig. 2. CL spectra for the enstatite indicated by cross marks (Fig. 1a). 


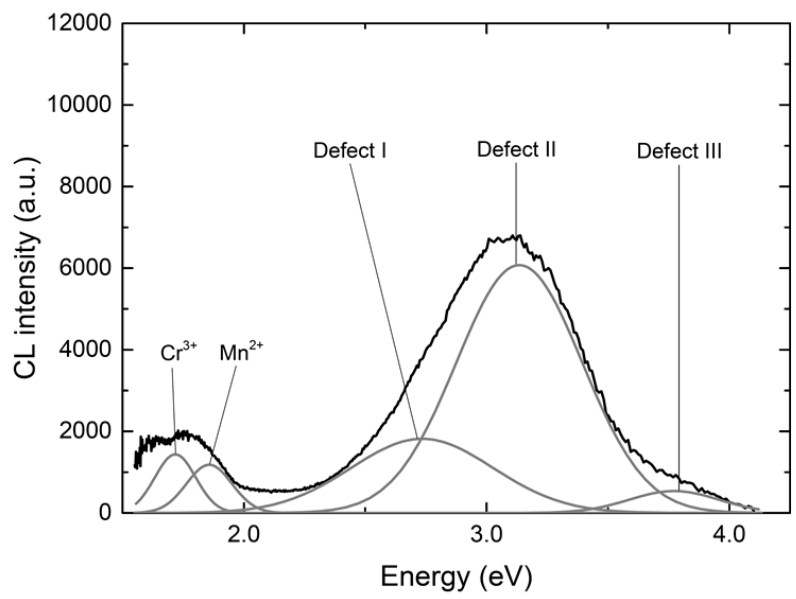

Fig. 3. Deconvolution of CL spectrum of blue-CL enstatite in energy units by Gaussian curve fitting.

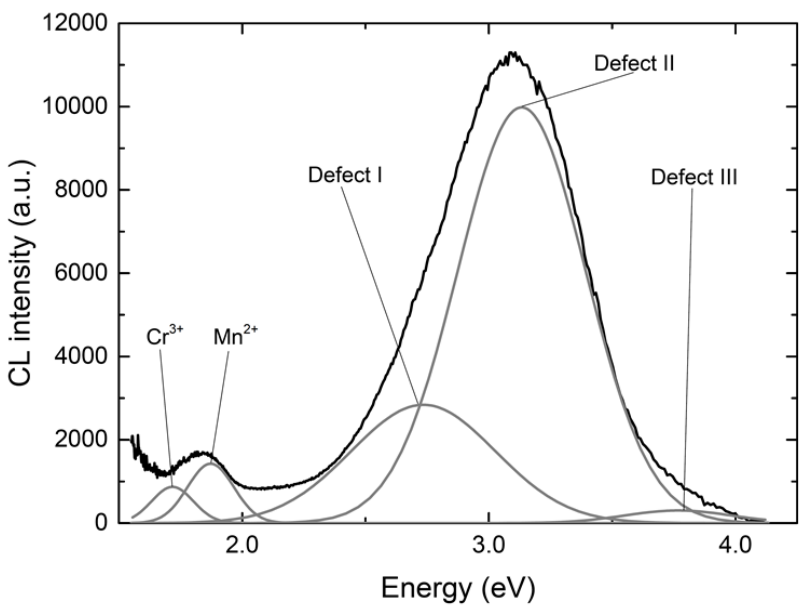

Fig. 4. Deconvolution of $C L$ spectrum of light-blue-CL enstatite in energy units by Gaussian curve fitting.

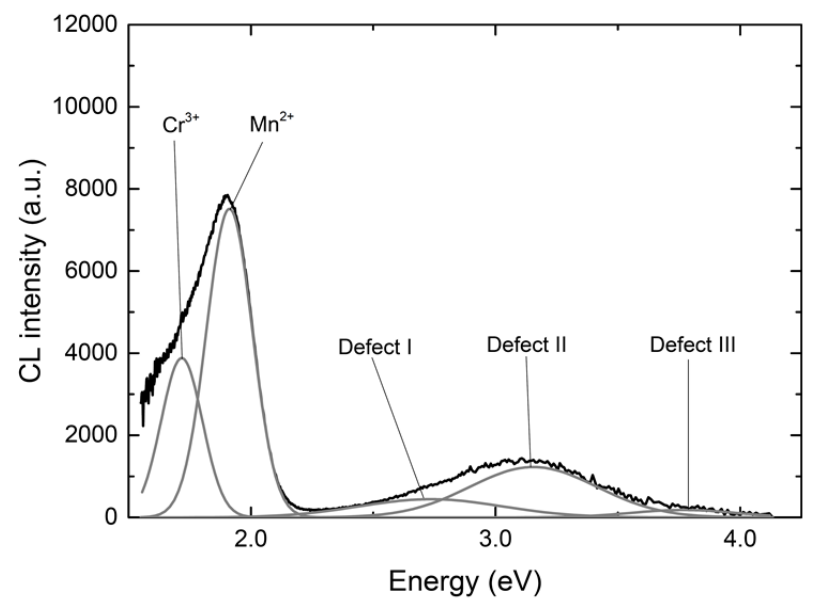

Fig. 5. Deconvolution of CL spectrum of red-CL enstatite in energy units by Gaussian curve fitting. of ${ }^{4} \mathrm{~T}_{1 \mathrm{~g}} \rightarrow{ }^{6} \mathrm{~A}_{1 \mathrm{~g}}$. Both of $\mathrm{Cr}^{3+}$ and $\mathrm{Mn}^{2+}$ centers have been recognized in extraterrestrial and synthetic enstatite (Steele, 1988; Moncorgé et al., 1999; Catalano et al., 2014).

According to Ohgo et al. (2015), the component at $2.73 \mathrm{eV}$ can be assigned to an emission center (Defect I) related to 'intrinsic defect' formed during crystal growth. Such defect center has been detected in synthetic enstatite without any activator and quencher ions (e.g., Lofgren and Dehart, 1992). An analogous intrinsic defect center also has been found at $2.75 \mathrm{eV}$ in synthetic forsterite, which is one of common Mg-silicate minerals associated with enstatite in meteorites. Furthermore, forsterite has emission components of $\mathrm{Cr}^{3+}$ ion at $1.65-1.72 \mathrm{eV}, \mathrm{Mn}^{2+}$ ion at $1.92 \mathrm{eV}$, defect center at 2.75 and $3.15 \mathrm{eV}$ (Gucsik et al., 2012), all of which accord closely with corresponding components obtained from the CL spectra of the enstatite in zone 1, 2 and 3. Ohgo et al., (2015) presumed that the emission component at 3.13-3.15 eV might be due to the defect center (Defect II) related to structural distortion of $\mathrm{T}(\mathrm{Si}, \mathrm{Al})-\mathrm{O}$ chain when $\mathrm{Al}$ substitutes for $\mathrm{Si}$ and/or deformation of the lattice due to an incorporation of $\mathrm{Ca}$ and $\mathrm{Ti}$ ions. In the case of measured enstatite, however, too low concentrations of $\mathrm{Ca}$ and $\mathrm{Ti}$ makes more difficult to judge the effect of impurity elements on the lattice in the enstatite (Table 1). According to Ohgo et al. (2015), the emission component at $3.77 \mathrm{eV}$ in zone 1-3 enstatite might be related to the defect center (Defect III) attributable to cosmic-ray irradiation on the surface of the parent body and during traveling in space. Cosmic rays with high energy could flick out oxygen in enstatite crystal structure and form oxygen vacancy related to defect center with a near-UV emission.

\section{Formation of CL zonation}

Color CL image (Fig. 1) shows four CL zones arranged in a concentric pattern. As demonstrated by Zhang et al. (1996), the CL of the enstatite in E-chondrite reflects a petrographic type and a peak temperature during thermal metamorphism in space. Therefore, thermal history of Y-86004 might be recorded as its CL zonation. Y-86004 experienced a melting on the surface of a parent body possibly related to a heavy shock event (Lin and Kimura, 1998) and a rapid cooling from the melt. It is supported by the presence of tridymite, which emerges by a quenching from high temperature $\left(867<\mathrm{T}<1470^{\circ} \mathrm{C}\right)$ (Swamy et al., 1994; Kimura et al., 2005). Therefore, all of the enstatite in Y-86004 were formed in a quenching process near surface of the parent body, suggesting that original enstatite in Y-86004 should be Oen with a blue CL emission.

The result of polarization microscopy and Raman spectroscopy show two types of enstatite with blue and light-blue CL in zone 2, former of which is virtually identical to Oen with a blue emission in zone 1. The light-blue enstatite has two defect centers of Defect I and Defect II, whereas the enstatite is identified as Oen. It is 
characterized by the Defect II not detected in the blue enstatite. Inasmuch as the meteorite experienced a flash heating above the melting point of the enstatite, the heating and cooling process during a falling through the atmosphere might affect a creation of defect center (Defect II) and alteration of existing defect (Defect I). Therefore, according to Gasparik (1990), some portion of the enstatite in zone 2 probably might have experienced a phase transition from Oen to protoenstatite (Pen) during a flash heating, which occurs at near $1273 \mathrm{~K}$. In this case, the enstatite with blue CL considerably survived from the original enstatite the same to one in zone 1, suggesting the temperature at around $1273 \mathrm{~K}$. When Pen is rapidly cooled, the phase transition involves physical stress, which might create defect center (Defect II) in the structure.

The enstatite in zone 3 is identified as LT-Cen by a Raman spectroscopy. This result is also supported by the peak energy of the emission component related to $\mathrm{Mn}^{2+}$ impurity. According to Ohgo et al. (2015), CL feature of red emission is useful to distinguish between Oen and LT-Cen phases. In the terrestrial enstatite, Oen has an emission component of impurity $\mathrm{Mn}^{2+}$ ion at $1.85 \mathrm{eV}$, but at $1.90 \mathrm{eV}$ for LT-Cen. The enstatite in zone 3 has a corresponding component at $1.92 \mathrm{eV}$, suggesting identification of LT-Cen. According to Gasparik (1990), when the Oen experienced high temperature at a temperature near the melting point of enstatite, it transfers from Oen and Pen to HT-Cen, which is stable near the melting point at $1831 \mathrm{~K}$. Therefore, red-CL enstatite in zone 3 might be formed by a rapid quenching from HT-Cen at around $1831 \mathrm{~K}$ due to structural similarity between LT-Cen and HT-Cen. The enstatite in zone 3 has almost none of blue emission related to the defects centers, implying the elimination of lattice defect by the elevated temperature near the melting point without structural stress in the transition between HT-Cen and Oen.

Y-86004 suffered a heavy ablation on its surface, which took away melting materials from the meteorite body in a short period. Zone 4 was formed during such ablation with amorphousization of enstatite-rich materials at the surface of the meteorite. Therefore, the surface of the meteorite has been exposed at and above the temperature of a melting point $(>1831 \mathrm{~K})$ of the enstatite.

Y-86004 was abruptly heated for a short time when it entered the earth's atmosphere, and rapidly quenched in the Antarctic ice immediately after its falling. In this study, the enstatite with a background of previous phases corresponding to the elevated temperatures can be characterized by CL imaging and spectroscopy, which reveals a mechanism of CL color zonation found in Y-86004.

\section{Estimation of thermal distribution in the meteorite}

We have conducted to evaluate the temperate history of Y-86004 during heating when the meteorite entered into the atmosphere. In general, typical falling object collides with the Earth's atmosphere at velocities of 12$20 \mathrm{~km} \cdot \mathrm{s}^{-1}$ (Bottke et al., 1994), where the most likely impact angle is $45^{\circ}$ (Shoemaker, 1962). According to Sears (1975), the time to flash heating of meteorite (luminous flight time) is a few tens of seconds. When thermal conductivity equation proposed by Melcher (1979) is simplified case of $\partial T / \partial t=0$ (steady-state as $T$ : temperature $(\mathrm{K})$ at depth $d(\mu \mathrm{m})$ and $t$ : the time) assumed, the following equation may be obtained:

$T=T_{\mathrm{m}}+T_{0} \exp \left\{-\left(v_{\mathrm{w}} / k\right) d\right\}$

where $T_{\mathrm{m}}$ is the ambient temperature $(\mathrm{K}), T_{0}$ is the surface temperature of meteorite $(\mathrm{K})$. In this case, the conduction of heat into a meteorite during flash heating may be estimated by approximating the meteorite surface as an infinite slab. Surface temperature of the meteorite might be at $1831 \mathrm{~K}$, whereas the ambient temperature at $193 \mathrm{~K}$ (Rawer, 1984). Density of meteorite is $3.313 \times 10^{3} \mathrm{~kg} \cdot \mathrm{m}^{-3}$, thermal conductivity of $4.19 \mathrm{~W} \cdot \mathrm{m}^{-1} \cdot \mathrm{K}^{-1}$ and specific heat of $8.24 \times 10^{2} \mathrm{~J} \cdot \mathrm{kg}^{-1} \cdot \mathrm{K}^{-1}$ were employed for the calculation referring to thermodynamic properties of the orthopyroxene (Kobayashi, 1974). When the heating duration is assumed to be 5-20 seconds according to Sears (1975), we obtained temperature profiles across the meteorite (Fig. 6).

The result of CL examination suggests that zone 2 in the range of the depth from surface between $\sim 200$ and $\sim 900 \mu \mathrm{m}$ might be heated at around $1273 \mathrm{~K}$, which is the transition temperature from Oen to Pen. Zone 1 was not heated up to $1273 \mathrm{~K}$ due to the presence of only Oen with a blue CL. Zone 3 between $\sim 100$ and $\sim 200 \mu \mathrm{m}$ might be expected to be heated up to the melting point of the enstatite at $1831 \mathrm{~K}$ due to the presence of HT-Cen supposed by the CL spectroscopy. The elevated temperatures in the zone estimated from the result of CL analysis might be consistent with the temperatures in corresponding depth from the surface calculated from the duration of $20 \mathrm{sec}-$ ond (Fig. 6), which is able to be adapted due to allowable values compared to previously obtained ones (e.g., Sears,

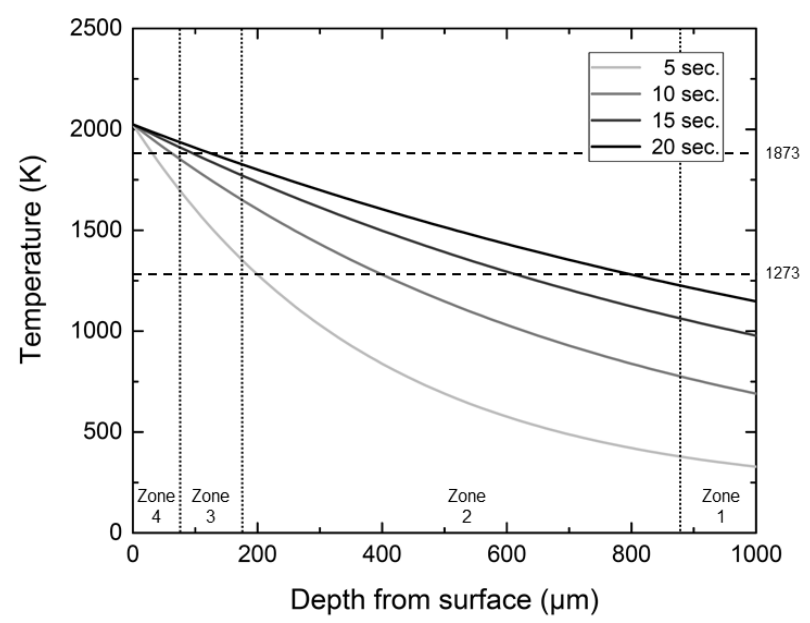

Fig. 6. Comparison of theoretical temperature profiles. Heating duration assumed 5-20 seconds. 
1975). Therefore, this result supports the presumption of zonation mechanism due to phase transitions of the enstatite in Y-86004 during a flash heating when it entered the earth's atmosphere. As mentioned above, CL imaging and spectroscopy are useful methods to provide valuable information on the crystal-chemical properties of the minerals occurring in terrestrial and extraterrestrial materials.

\section{ACKNOWLEDGEMENTS}

We are deeply thankful to Y. Sawada for chemical analyses by EPMA and helpful suggestions on enstatite chemistry, and to H. Hyodo for heating experiments and helpful suggestions on physico-chemical properties of pyroxene.

\section{REFERENCES}

Bottke WF Jr, Nolan MC, Greenberg R and Kolvoord RA, 1994. Collisional lifetimes and impact statistics of near-Earth asteroids. In Hazards due to comets and asteroids, edited by Gehrels T., Tucson: The University of Arizona Press, 337-357.

Catalano M, Bloise A, Pingitore V, Miriello D, Cazzanelli E, Giarola M, Mariotto G and Barrese E, 2014. Effect of Mn doping on the growth and properties of enstatite single crystals. Crystal Research and Technology 49: 736-742, DOI 10.1002/crat.201400102.

Derham CJ, Geake JE and Walker G, 1964. Luminescence of enstatite achondrite meteorites. Nature 203: 134-136, DOI 10.1038/203134b0.

Gasparik T, 1990. Phase relations in the transition zone. Journal of Geophysical Research 95: 15751-15769, DOI 10.1029/JB095iB10p15751.

Gucsik A, 2009. Shock metamorphism of terrestrial impact structures and its application in the Earth and planetary science. In Cathodoluminescence and its application in the planetary science, edited by Gucsik A., Berlin Heidelberg, Springer-Verlag, 23-43.

Gucsik A, Tsukamoto K, Nishido H, Miura H, Kayama M, Ninagawa K and Kimura Y, 2012. Cathodoluminescence microcharacterization of forsterite in the chondrule experimentally grown under super cooling. Journal of Luminescence 132: 1041-1047, DOI 10.1016/j.jlumin.2011.12.011.

Ikenaga M, Nishido H, Ninagawa K, 2000. Performance and analytical conditions of cathodoluminescence scanning electron microscope (CL-SEM). Bulletin of Research Institute of Natural Sciences Okayama University of Science 26: 61-75.

Keil K, 1968. Mineralogical and chemical relationships among enstatite chondrites. Journal of Geophysical Research 73: 6945-6976, DOI 10.1029/JB073i022p06945.

Kimura M, Weisberg MK, Lin Y, Suzuki A, Ohtani E and Okazaki R, 2005. The thermal history of the enstatite chondrites from silica polymorphs. Meteoritics and Planetary Science 40: 855-868.
Kobayashi Y, 1974. Anisotropy of thermal diffusivity in olivine, pyroxene and dunite. Journal of Physics of the Earth 22: 359-373.

Lin Y and Kimura M, 1998. Petrographic and mineralogical study of new EH melt rocks and a new enstatite chondrite grouplet. Meteoritics and Planetary Science 33: 855-868.

Lofgren GE and Dehart JM, 1992. Dynamic crystallization studies of enstatite chondrite chondrules: cathodoluminescence properties of enstatite. Abstracts of the Lunar and Planetary Science Conference 23: 799-800.

Marfunin AS, 1979. Spectroscopy, Luminescence and radiation centers in minerals. Springer, Verlag, New York.

Melcher CL, 1979. Kirin meteorite: temperature gradient produced during atmospheric passage. Meteoritics and Planetary Science 14: 309-316.

Matsunami S, Ninagawa K, Nishimura S, Kubono N, Yamamoto I, Kohata M, Wada T, Yamashita Y, Lu J, Sears D and Nishimura H, 1993. Thermoluminescence and Compositional Zoning in the Mesostasis of a Semarkona Group A1 Chondrule and New Insights into the Chondrule-forming Process. Geochimica et Cosmochimica Acta 57: 2101-2110, DOI 10.1016/0016-7037(93)90096-F.

Moncorgé R, Bettinelli M, Guyot Y, Cavalli E, Capobianco JA and Girard S, 1999. Luminescence of $\mathrm{Ni}^{2+}$ and $\mathrm{Cr}^{3+}$ centers in $\mathrm{MgSiO}_{3}$ enstatite crystals. Journal of Condensed Matter 11: 6831-6841, DOI 10.1088/0953-8984/11/35/319.

Ohgo S, Nishido H and Ninagawa K, 2015. Cathodoluminescence characterization of enstatite. Journal of Mineralogical and Petrological Science 110: 241-246, DOI 10.2465/jmps.150713b.

Rawer K, 1984. Modelling of Neutral and Ionized Atmospheres. In Handbuch der Physik Encyclopedia of Physics, edited by Rawer K., Heidelberg, Springer Verlag, 223.

Reid AM, Bunch TE and Cohen AJ, 1964. Luminescence of orthopyroxenes. Nature 204: 1292-1293, DOI 10.1038/2041292a0.

Rubin AE and Scott ERD, 1997. Abee and related EH chondrite impactmelt breccias. Geochimica et Cosmochimica Acta 61: 425-435, DOI 10.1016/S0016-7037(96)00335-3.

Sears DW, 1975. Temperature gradients in meteorites produced by heating during atmospheric passage. Modern Geology 5: 155-164.

Shoemaker EM, 1962. Interpretation of lunar craters. In Physics and astronomy of the Moon, edited by Kopal Z., New York: Academic Press, 283-359.

Steele IM, 1988. Enstatite cathodoluminescence: Assignment of emission peaks to $\mathrm{Cr}$ and $\mathrm{Mn}$ and application to quantitative analysis. Meteoritics and Planetary Science 23: 303.

Swamy V, Saxena S, Sundman B and Zhang J, 1994. A thermodynamic assessment of silica phase diagram. Journal of Geophysical Research 99: 11787-11794, DOI 10.1029/93JB02968.

Weisberg MK, Prinz M and Fogel RA, 1994. The evolution of enstatite and chondrules in unequilibrated enstatite chondrites: Evidence from iron-rich pyroxene. Meteoritics and Planetary Science 29: $362-373$.

Yanai K and Kojima H, 1995. Catalog of the Antarctic meteorites. National Institute of Polar Research, Tokyo, Japan, 230.

Zhang Y, Huang S, Schneider D, Benoit PH, Dehart JM, Lofgren GE and Sears DWG, 1996. Pyroxene structures, cathodoluminescence and the thermal history of the enstatite chondrites. Meteoritics and Planetary Science 31: 87-96. 